\title{
Educational Centres as Knowledge Organisations Training Future Knowledge Workers: The Role of IT
}

\author{
J. Osorio, C. Zárraga and J. Rodríguez \\ University of Las Palmas de Gran Canaria, E-35017 Las Palmas de Gran Canaria, Spain \\ Fax: +34 928 451829, E-mail: Osorio @, empresariales. ulpgc. es
}

Key words: Information Technology, Knowledge Management, Education, ITEM Systems

Abstract: The main objective of this paper is to propose an IT related educational framework for centres which are responsible for future knowledge workers primary schools, high schools, and universities. First, we analyse the latest changes in the business world due to the arrival of a new knowledge era. According to empirical and theoretical evidence, the first step necessary to succeed in knowledge management seems to be information technology (IT). After clarifying both the conceptual differences between information and knowledge, and the different knowledge types which are necessary to be managed, we analyse how IT can be a very useful tool for knowledge management in organisations. Second, we reflect upon the academic and social aims of educational centres, relating them to the inherent aims of knowledge based organisations. The goal is to try to integrate two perspectives that are not always easy to merge. As mentioned, the key point throughout this process can be IT, but it is necessary to train students of different levels in the basic skills, not only to accomplish the academic objectives, but also bearing in mind the role they are going to play in a more globally competitive environment. Finally, we consider the influence that these changes can have on educational centres, making them adapt to the environment by means of a learning attitude that allows them to become real knowledge centres. In this respect, information technology for educational management(ITEM) systems can play a vital role as catalysts for the process of change. 


\section{INTRODUCTION}

The economy of every country is a direct reflection of its degree of business structure development. Corporations, the major employment creators, are under growing pressure from the increasingly competitive environment. Therefore, they have to continuously adapt and transform their business practices to survive. In this adaptive process, corporations are focusing their strategies more and more on the so-called intangible resources, fundamentally knowledge management and corporate learning. This trend has meant a dramatic change in traditional business management practices which were typically centred around physical assets.

This recent trend affects the training and skills that corporations now require from their present and future employees. Clerical and non-clerical workers are becoming knowledge workers and an important part of theirjob is to manage corporate knowledge appropriately. Consequently, educational centres of every level, as the main suppliers of qualified human resources, must rapidly adapt to the demands of the job market and give students the necessary skills to work successfully within corporations. The success of educational centres and, in many cases, their very survival, will depend on the compatibility of their students' training with the requirements of business corporations.

One key point in achieving this is the education and training given to students in information technology (IT) matters. Empirical evidence shows that the very first step necessary to succeed in knowledge management is to know and to master IT potential. Therefore it is necessary at every educational level - primary school, high school and university - to clearly identify the likely missions and functions of the respective graduates in the jobs in today's market place. Consequently, an important task for those responsible for education is to effectively plan the IT tools that students at each level must know and master.

Bearing in mind previous considerations, this paper attempts to propose an IT educational framework with the most suitable tools, objectives and training methodologies at each educational level. This framework must be adapted to the socially established general educational objectives and, at the same time, satisfy the demands of the business world in which most students will develop their professional activities in the future.

To achieve this goal it is also necessary to redefine the role of educational centres. Knowledge ${ }^{1}$ is the most important resource that educational centres have in order to ensure that the output (students who have completed their education) are prepared for the functions that they will

${ }^{1}$ Not only the knowledge that they pass on to students, but, above all, the know-how to carry out the educational function in a more effective way. 
perform in the future. In this process of knowledge acquisition, the centres become organisations that learn and the ITEM constitutes an important agent for learning, making a definitive contribution to defining this new role of educational centres.

The paper starts with an analysis of the latest changes in the business world due to the new knowledge era, which leads us to the conclusion that the knowledge management efforts of companies begin with the implementation of IT. Following this, we explain the role of IT in organisations whose competitive advantage is based on knowledge management using the hypertext style of organisational structure, as well as the new concept of heterarchy.

At this point, we review the social and academic aims of the educational system at the present time, which constitute the reference that must be taken into account. This is because companies' goals could cause conflict between their demands for employees' training and the socially settled objectives of the educacional system. However, it is important for the growth of joint attempts to closely integrate both sides - academic and economic - to improve the general performance at all levels, including the social one. Hence, knowing the business trend - that of companies relying on better knowledge management - and a potential way of integrating it with education aims by means of IT, we propose an educational framework for IT, trying to identify the computer skills that could be included in the formative curriculum of students according to their educational level.

To be able to put this educational framework into practice it is necessary to redefine the role of the educational centres. We consider a vision based on knowledge management to be necessary, and this is acquired after a process of continuous learning about how to teach or educate in a better way. With this purpose in mind, we reflect at the end of the paper that, in order to be successful, it is necessary to know how to take advantage of the potential offered by IT, and more specifically of the diverse tools that make up ITEM. By combining qualified human resources with the use of IT, the appropriate conditions for those changes required by the future environment can be created.

\section{KNOWLEDGE AND INFORMATION TECHNOLOGY}

Static theories of competition, associated with neoclassical microeconomics and the "structure-conduct-performance" school of industrial economics, are being displaced by the more dynamic approaches associated with the Austrian school of economics, especially with Schumpeter's concept of competition as a process of "creative destruction" (Schumpeter, 1934). This displacement has had profound implications for strategic management 
thinking and it has generated the resource-based view of the firm, which places more emphasis on the "supply-side" than the "demand side". This new strategic view has been closely associated with recent works on organisational capabilities, such as Prahalad and Hamel's work (1990), which argues that sustainable competitive advantage is dependent upon building and exploiting "core competences". These are capabilities which are fundamental to a firm's competitive advantage and which can be deployed across multiple product markets.

Indeed, competitive conditions in product markets are driven, in part, by the competitive conditions in resource markets. Thus, the speed with which positions of competitive advantage in product markets are undermined, depends upon the ability of challengers to acquire the resources needed to initiate a competitive offensive. Sustainability of competitive advantage, therefore, requires resources which are idiosyncratic (and therefore scarce), and not easily transferable or replicable. These criteria point to knowledge as the most strategically important resource which firms possess.

Many researchers have pointed out that for many firms their ability to create, share, and use knowledge will have a major impact on their future competitiveness; and some even state that the only sustainable competitive advantage in the future will be good or excellent organisational knowledge creation and good knowledge management(Toffler, 1990; Drucker, 1993; El Sawy et al., 1997; Teece, 1998; Miles et al., 1998). One hypothesis is that theories of organisational knowledge creation and a resource-based view can give new ideas on how to design and implant IT. Nowadays, there are two main reasons for the changing role of IT. First, there is a paradigm shift from information processing to knowledge creation. Second, the literature on knowledge management is to a large extent ignoring IT (Carlsson et al., 1996).

On the other hand, from the empirical point of view, studies such as that conducted in 1997 by the Ernst \& Young Center for Business Innovation, whose objective was to describe what firms are doing in order to manage knowledge and what else they think could be or should be done, show that $22 \%$ of the 431 US and European organisations studied think that restrictions over IT are a hindrance to the transfer of knowledge. Furthermore, many companies are progressing along similar lines when their knowledge management efforts start with the implementation of a technological capability, although when respondents were asked whether their organisations' ability to compete based on knowledge depends more upon people, process or technology issues, their aggregate responses placed the emphasis heavily on people $(50 \%)$, with the other two areas carrying equal secondary weight $(25 \%$ each). So, there is evidence of the knowledge management efforts of companies, starting with the implementation of a 
technological capability, which allows them (at least in principle) to capture and share corporate know-how. Only after this capability exists do the firms realise how vital other factors are (Ruggles, 1998).

\section{INFORMATION TECHNOLOGY: A TOOL FOR KNOWLEDGE MANAGEMENT}

To explain the role of information technology in organisations whose competitive advantage is based on knowledge management, we use the hypertext style of organisational structure, defined by Nonaka and Takeuchi (1995), as well as the new concept of heterarchy versus the classical concept of hierarchy, as defined by Hedlund (1994). The heterarchy arises from: (1) the dispersal of knowledge and strategic action initiative to "lower levels"; (2) shifting bases of leadership and composition ofteams; (3) the importance of lateral internal communication and integration through shared culture; and (4) change of roles at all levels of the corporation. Therefore, a business organisation should have a nonhierarchical, self-organising structure working in tandem with its formal hierarchical structure. The most appropriate metaphor for such a structure comes from a "hypertext", which was originally developed in computer science. A hypertext organisational structure will have three layers: the business-system layer, the project-team layer, and theknowledge-base layer.

The central layer is the "business-system" layer, in which normal, routine operations are carried out. Since a bureaucratic structure is suitable for conducting routine work efficiently, this layer is shaped like a hierarchical pyramid, that is, this layer has a strong focus on vertical communication (Nonaka \& Takeuchi, 1995). The IT community knows quite well how to design and implement systems for the business-system layer, mainly from an information processing perspective. Computer-based systems such as transaction processing systems, accounting information systems, and management information systems are good examples of this type of system (Carlsson et al., 1996). 


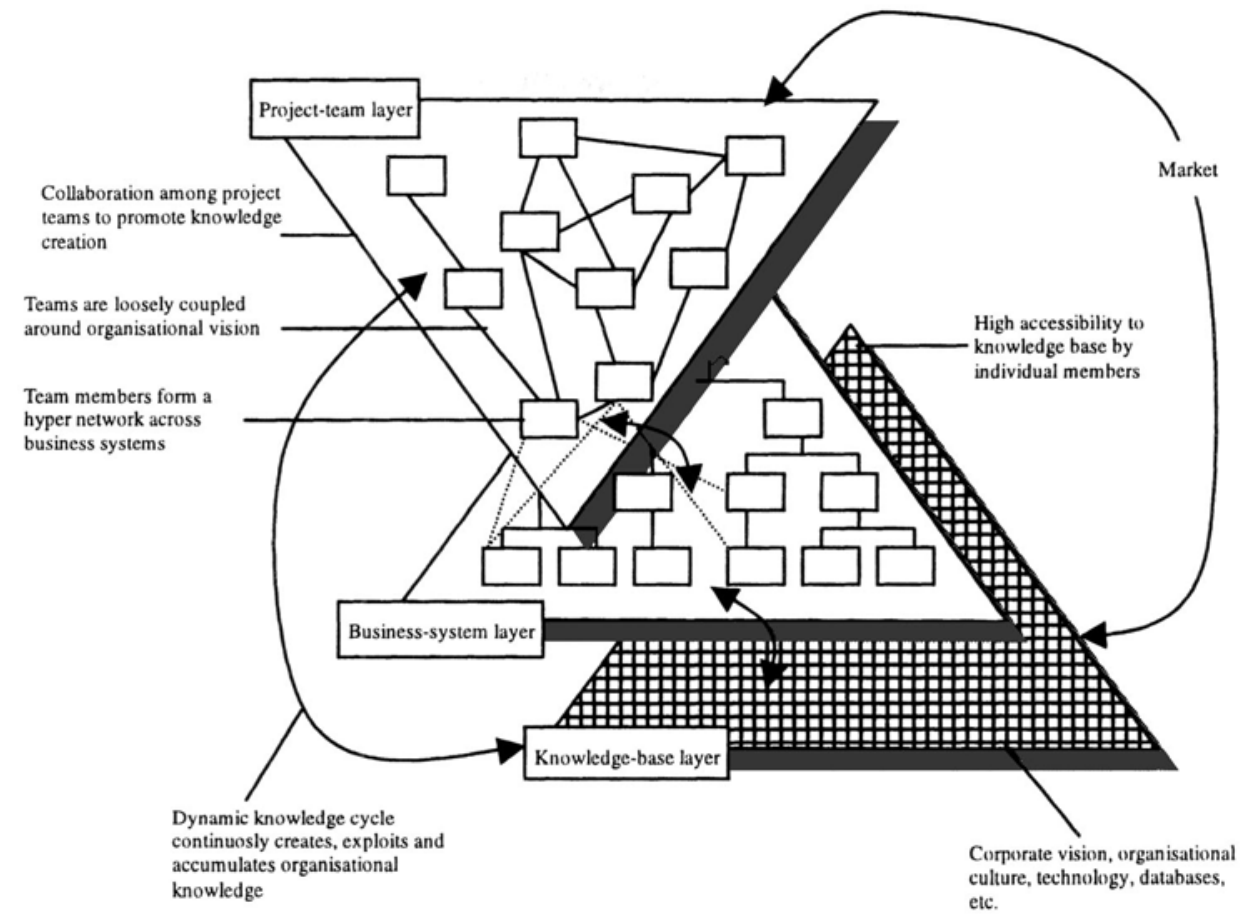

Figure 1. Hypertext organisation. Source: Nonaka and Konno (1993)

At the bottom is the "knowledge-base" layer, where organisational knowledge generated in the above two layers is recategorised and recontextualised in accordance with the firm's corporate vision, organisational culture, and technology. Corporate vision provides the direction in which the company should develop its technology or products, and clarifies the "field" in which it wants to play. Organisational culture directs the mindset and action of every employee. Technology helps to make knowledge accessible to the whole organisation (Nonaka \& Takeuchi, 1995). For this, the key is that everybody in the organisation is aware of who knows what, who can help with what or who can use new information (von Hippel, 1988; Carlsson et al., 1998). Information technology, as data warehousing or knowledge repositories and decision support tools, can make it possible for an organisation to store and to make accessible "what we know" as an organisation. Whatever the level of sophistication, repositories essentially compile data, information and knowledge through, and in the form of, processes that enable access throughout the company. In time, these repositories contribute to the maintenance of the firm's shared intelligence and organisational memory. 


\section{THE ROLE OF THE EDUCATIONAL SYSTEM}

In the light of the described managerial reality, we believe that the educational system has to respond to the demand for qualified personnel coming from organisations whose competitiveness relies basically on knowledge management. Consequently, based on the theoretical and empirical evidence outlined previously, our objective centres on identifying what is the IT that, while fostering the specific objectives of educational centres (we can refer to them as the 'supply'), also prepares the students appropriately for their future incorporation into the companies (consequently the 'demand').

It can be stated that the existence of educational systems is a reality for all civilisations and, over the course of time, they have evolved, thus changing their pedagogic objectives. At the present time, almost every country belonging to the OECD designs its educational system in order to (Gairín,1992):

- Boost the critical capacity;

- Provideknowledge;

- Develop the values of respect, autonomy and responsibility;

- Favour the processes of collaboration;

- Assist the diversity;

- Encourage the integration process; and

- Cultivate democratic values.

It is important to remember that the accomplishment of these pedagogic goals can be extremely difficult when the importance of the specific demands coming directly from the business system is not perceived. We refer here to the glass bubble syndrome, which means that educators are, on occasion, out of touch with the social and professional reality in which their present students will perform their work in the future. We believe that it is necessary for educational professionals, both academic and management staff, to be aware of the professional demands coming from the companies. As a first step, it might be useful to consider the educational centre itselfas a knowledge management centre, in which the objective should be to reach excellence, promoting a better and more efficient spread and management of knowledge. This way, in the educational centres themselves, they would appreciate the importance of suitable teaching and application of the tools, including IT, that can contribute to the attainment of this goal, so stimulating feedback processes and a continuous improvement starting from the educational centres' own experience. The implications that the latter can have for ITEM systems may be crucial in facing the future. 
Now centring on our objective, before proceeding to the identification of how IT can improve not only the goals of educational centres but also the market-specific training of future employees, it is worth identifying three different areas in the IT field: hardware, software and telecommunications. With reference to the first, hardware, we can now state that the personal computer (PC) constitutes the present, and most likely future, standard platform, due, among other reasons, to its growing power, integration capacity, and ease of use as well as its low cost. Companies tend to focus their information management processes around PCs, thus abandoning technological formulas which not long ago constituted the defacto standard. On the other hand, insofar as telecommunications is concerned, it can to be said that the TCP/IP protocol has become the basis which has allowed the dramatic development of communications in recent years. It is foreseeable that in the next few years computers will work exclusively on this protocol in any type of communication, both internal and external to the organisation.

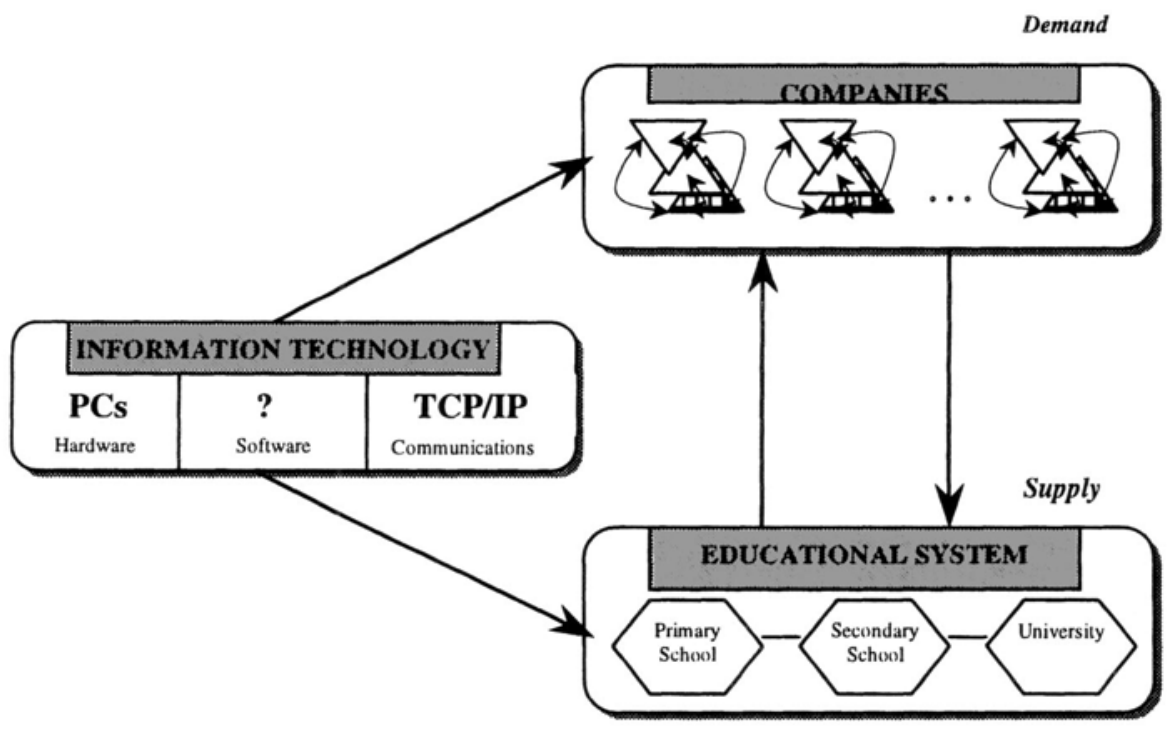

Figure 2. IT educational framework

It is not so easy, however, to identify optimal technological solutions in the software field. The wide range of computer applications and software developers produces some confusion when trying to identify the tools that should be incorporated as a fundamental part of students' education. Nevertheless, we believe that bearing in mind the personnel needs of companies on the one hand and the pedagogic objectives established by the 
educational system on the other, and with the added advantage of knowing what will probably be the standard in hardware and telecommunications, we can outline which software applications should be incorporated into the educational curriculum. At this point it would be appropriate to differenciate between educational levels according to the specific objectives associated with each educational stage. In summary, the IT educational framework now taking shape is represented in Figure 2, where the companies that nowadays base their competitiveness on knowledge management interact with the current educational system, IT being the fundamental nexus among them.

\section{AN EDUCATIONAL FRAMEWORK FOR IT}

Bearing in mind the considerations previously outlined, we will now attempt to define more precisely what the software tools should be, and to what end they should be included in the formative curriculum of students according to their educational level. It is important not to forget that when teaching software it is necessary to make an effort to concentrate on the basic and stable principles; those always remain, independent of the developer and the version of the computer application. This way it can be assured that the student is prepared to adapt to any format change that might be carried out on the tool.

Primary education (approximately 6-12 years). Although the specific educational objectives vary according to country and culture, it can be said that the main objective at this level consists of instilling in the students a base of academic knowledge and social attitudes that allow them to adapt to their social environment. The use of computers as a complement to classes, helping students to learn by means of educational games and tutorials, can also notably contribute to their familiarisation with a tool that will accompany them throughout their professional lives. Once the basics of the tool (the PC) are known to the students, it is worth letting them know the potential offered by the Internet, albeit always closely monitored by the teacher. Showing the existence of other cultures, promoting communication with students in other parts of the world, as well as teaching the possibility of accessing knowledge through the Internet permits attainment of both educational and social objectives at the same time at this educational level.

Secondary education (approximately 12-18 years). Two main groups of students can be distinguished: on the one hand, the students that join the professional world on concluding this educational level and, on the other hand, the students that stay in the educational system to continue with 
university careers. Regarding the first group, companies usually employ personnel with secondary studies fundamentally to work in operational activities. Companies expect employees at this level to have enough knowledge and social skills to successfully integrate into their workforce. School-leavers are expected to be familiar with the operation of productivity tools, such as word processors, spreadsheets and databases. Companies that base their competitiveness on knowledge also require employees with sufficient ability to contribute, by means of IT, to the improvement of products and services, adding value in the process and increasing the quality offered to clients. Students that stay in the educational system to continue with university careers, should also know the productivity tools in order to use them during their future studies.

It can be gathered from the above that at this level it is necessary to teach the productivity tools, but with the basic difference that this teaching places emphasis on the students' ability to model problems by means of the computer. The objective is to teach students to be not mere users of software applications, but rather to know how to create simulation and optimisation models. Finally, from the point of view of the development of collaboration attitudes, it is important at this level to encourage collaborative work, both internally in the class by means of groupware tools on a local area network (LAN), and externally by means of groupware tools on the World Wide Web (WWW). If students begin to use this type of tool at this level, the likelihood of its continued use in the university or in the company increases, thus promoting a desirable attitude in all students and workers.

University education. At this level there are a wide range of professional careers available. Graduate students are mostly recruited to middle or top management positions in a company. They are expected to have sociotechnical capabilities, the capacity for middle and long-term planning, and problem solving abilities. Knowledge management based companies also expect this grade of employee to be able to instill in the rest of the organisation the importance of the practices of knowledge management as well as to be pioneers in the use of tools that facilitate this objective. On the other hand, nowadays IT is, as has been formerly shown, the first step towards the operationalisation of knowledge management in companies. Therefore, the university student should know the whole range of possibilities offered by professionally related software applications at any given moment, as well as having the capacity to know, to distinguish and to assimilate the new tools that are continually being launched. 
At university level it should be assumed that students manage the productivity tools with ease, and that the use of the Internet as a means of acquiring knowledge and of group collaboration is second nature. Depending on the degree chosen, the students should be trained in the use of specific tools with potential for their professional careers, but always stressing the underlying models of the tool and not incidental matters like operational handling. The emphasis should be centred on expert systems (ES), decision support systems (DSS) and executive information systems (EIS). These tools will vary continually throughout the professional career of the knowledge worker, but he/she will have sufficient skills to adapt to the new challenges that their use implies vis-a-vis the objectives specified by the knowledge management based companies.

All the above-mentioned has, logically, important implications for educational centres in their potential new role of knowledge management centres. In short, these do function as such and their academic and management staff must be those responsible for achieving this. Information and its more effective use may be the key to educational centres, just like companies, reaching better performance levels. The mentioned software tools, in the hands of the academic and management staff, also constitute ITEM systems, one advantage of which is that "[the ITEM systems] provide more time for pupil contact, thus enhancing interaction, positive intervention, feedback and discussion with implications for a more collaborative learning environment"(Visscher \& Wild, 1997:271).

\section{A NEW VISION FOR EDUCATIONAL CENTRES}

Facing the challenges of the future and the demands arising from labour markets, educational centres should be aware of and react to the need to become centres of excellence. This is important if they want to offer society competent graduates and also attract new students who, with the proliferation of public and private, attendance-learning and distance-learning centres, will have more choice of study locations. For this reason, educational centres should take advantage of their resources and differential capabilities, exploiting their strengths and trying to reduce or eliminate their weaknesses.

Of all the resources of an organisation, the most important is knowledge, because it is the most difficult to transfer and replicate. Knowledge is generated in an individual way, and in our case the education system puts at each teacher's disposal the means to increase his or her individual knowledge. However, it is the responsibility of the centre to apply existing knowledge in the improvement of the educational process. The logic is to 
incorporate the knowledge of many performers (the teachers) efficiently and to promote the means that lead to an increased level of shared knowledge among the members of the centre. To attain this objective it is necessary to make the centre's members aware of the need to incorporate continuous learning into the day-to-day culture, thus transforming the workplace into what is called a learning organisation.

The learning process is long and continuous since organisations learn while they carry out their activities. This leads to an increase in the degree of knowledge and is translated into the capacity to achieve the desired results and to transform a centre into one of excellence. Furthermore, a series of abilities should be acquired within a set of activities, which include: (1) the systematic resolution of problems; (2) experimenting with new approaches to teaching; (3) learning from the experiences and better practices of other educational centres; and (4) the fast and efficient transfer of knowledge throughout the entire organisation (Garvin, 1993). Therefore, the challenge consists of making effective use of IT in order to contribute to the educational management of centres while understanding that it should also embrace the administration of knowledge, in other words, favouring the communication of individual knowledge among teaching staff so that it becomes a shared asset.

\section{CONCLUSIONS}

The relationship between the offer and the demand, as established by the neoclassic economists, is widely accepted to explain the operation of the market place. In a similar way, we can accept that an offer and demand relationship exists between educational centres and companies. A mutual and constant adaptation that has a bearing on the improvement of society and the economy is necessary. Companies are under numerous changes and pressures, one of which is the need to identify and appropriately manage the knowledge existent within them. IT is the basic instrument for managing this knowledge and requires qualified workers who know how to obtain the greatest possible benefit from it. The challenge for educational centres lies in learning how to incorporate the teaching of IT with that objective in mind, but it implies that they themselves also have to become knowledge management organisations.

It is true to say that, for many years, primary schools, secondary schoools and universities have incorporated IT courses into their programmes, and also that this has been a consequence of trying to adapt to social and economic changes. Most of the IT tools mentioned above are already taught at educational centres, but an in-depth analysis would show the merely instrumental nature that they are given. This is very similar to what 
happened in language teaching in non-English speaking countries some decades ago: English was taught and learnt as a complementary subject without stressing its imminent importance in a more global world where it was going to be necessary to master a common language. Continuing with the comparison, nowadays IT teaching seems like the mere acquisition of skills for using a computer package without showing their importance as potential knowledge vehicles from very early on in a child's life. The increase in use of IT in organisations in the near future is foreseeable as the importance of knowledge management becomes more and more recognised. Therefore, the point should be to change the perspective or philosophy while teaching IT in educational centres. That could have great impact on the educational culture, with some enthusiastically supporting it, and others reacting against it.

We consider that our view of a different philosophy when teaching IT in educational centres could promote discussion and consequently give rise to various implications for them. The first we have identified as the pressure on educational centres to become real knowledge management centres, thus constituting an asset for ensuring the quality of their output. In this way, we believe that ITEM systems can be crucial in this challenge. IT not only has to be taught, thinking of future knowledge workers, but it has also to be applied to make the centre itself a knowledge management based organisation. The latter gives rise to a new dimension for ITEM systems that justifies their importance and highlights the need to further research this area.

\section{REFERENCES}

Brown, J.S., \& Duguid, P. (1998). Organizing knowledge. California Management Review, 40 (3), $90-111$.

Carlsson, S.A., El Sawy, O.A., Eriksson, I., \& Raven, A. (1996). Gaining competitive advantage through shared knowledge creation: In search of a new design theory for strategic information systems. Proceedings of the 4th European Conference on Information Systems. Lisbon, Portugal, 2-4 July, 1996.

Cash, J.L., McFarlan, F.W., McKenney, J.L., \& Applegate, L.M. (1992). Corporate information systems management (3rd ed.). Boston, MA: Irwin.

Drucker, P.F. (1993). Post-capitalist society. Oxford: Butterworth Heinemann.

El Sawy, O.A., Eriksson, I., Carlsson, S.A., \& Raven, A. (1997). Shared knowledge creation spaces around the new product development process. Working Paper, University of Southern California.

Gairín, J. (1992). El proyecto curricular en el marco de una escuela renovada. In Orientaciones teórico-prácticas para la elaboración de proyectos curriculares. Madrid: Ministerio de Educación y Ciencia.

Garvin, D.A. (1993). Building a learning organization. Harvard Business Review, 71 (4), 7891. 
Hedlund, G. (1994). A model of knowledge management and the N-form corporation. Strategic Management Journal, 15, 73-90.

Hippel, E. von, (1988). The sources of innovation. New York: Oxford University Press.

Miles, G., Miles, R.E., Perrone, V., \& Edvinsson, L. (1998). Some conceptual and research barriers to the utilization of knowledge. California Management Review, 40 (3), 281-288.

Nonaka, I., \& Konno, N. (1998). The concept of Ba. California Management Review, 40 (3), 40-54.

Nonaka, I., \& Takeuchi, H. (1995). The knowledge-creating company. New Yord: Oxford University Press.

Prahalad, C., \& Hamel, G. (1990). The core competence of the corporation. Harvard Business Review, 68 (3), 79-111.

Ruggles, R. (1998). The state of the notion: Knowledge management in practice. California Management Review, 40 (3), 81-89.

Schumpeter, J.A. (1934). The theory of economic development. Cambridge, MA: Harvard University Press.

Teece, D. (1998). Capturing value from knowledge assets: The new economy, markets for know how, and intangible assets. California Management Review, 40 (3). 55-79.

The Ernst \& Young Center for Business Innovation and Business Intelligence (1997). Twenty questions on knowledge in the organization. Ernst \& Young. http://www.businessinnovation.ey.com/research/knowle/survey/survey.html.

Toffler, A. (1990). Powershift: Knowledge, wealth and violence at the edge of the 21st century. NewYork: BantamBooks.

Visscher, A., \& Wild, P. (1997). The potential of information technology in support of teachers and educational managers managing their work environment. Education and Information Technologies, 2 (4), 263-274. 